\title{
Sulforaphane increases Nrf2 expression and protects alveolar epithelial cells against injury caused by cigarette smoke extract
}

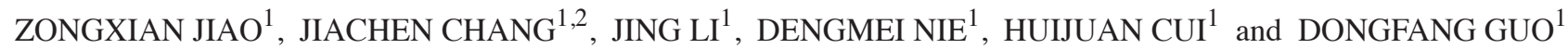 \\ ${ }^{1}$ Research Institute of Pathology, School of Basic Medical Sciences, Lanzhou University, Lanzhou, Gansu 730000; \\ ${ }^{2}$ Department of Pathology, Fangshan Maternal \& Child Health Hospital of Beijing, Beijing 102488, P.R. China
}

Received April 12, 2016; Accepted March 16, 2017

DOI: $10.3892 / \mathrm{mmr} .2017 .6700$

\begin{abstract}
Cigarette smoking is a primary risk factor for chronic obstructive pulmonary disease (COPD), as it damages epithelial cells through a variety of mechanisms. Sulforaphane (SFN) is an antioxidant agent, which exerts protective effects against cell damage by activating the nuclear factor erythroid 2 like 2 (NFE2L2; Nrf2). The present study was undertaken to investigate the effects and underlying mechanisms of SFN in preventing cigarette smoke extract (CSE)-induced oxidative damage to RLE-6TN rat lung epithelial cells. MTT assay was used to determine the cytotoxicity of SFN and CSE. The effect of SFN and CSE on cell cycle progression, apoptosis and intracellular reactive oxygen species (ROS) levels were analyzed using flow cytometry. Reverse transcription-quantitative polymerase chain reaction and western blotting were used to quantify mRNA and protein expression levels of Nrf2 respectively. SFN protected RLE-6TN cells from oxidative damage, potentially via increasing Nrf2 expression and reducing ROS levels. In addition, SFN attenuated G1 phase cell cycle arrest and abrogated apoptosis. Therefore, SFN protected alveolar epithelial cells against CSE-induced oxidative injury by upregulating Nrf2 expression. The results of the present study may provide theoretical support for the clinical use of SFN in patients with COPD.
\end{abstract}

\section{Introduction}

Chronic obstructive pulmonary disease (COPD) is a group of diseases associated with cigarette smoke, and it is becoming a primary cause of mortality and morbidity in humans. COPD is the fourth leading cause of mortality worldwide and the World Health Organization predicts it will become the third

Correspondence to: Dr Zongxian Jiao, Research Institute of Pathology, School of Basic Medical Sciences, Lanzhou University, 199 West Donggang Road, Lanzhou, Gansu 730000, P.R. China E-mail: jiaozongx@1zu.edu.cn

Key words: cigarette smoke extract, alveolar epithelial cells, sulforaphane, nuclear factor erythroid 2 like 2 leading cause by $2030(1,2)$. The disease is characterized by chronic airway inflammation, airflow obstruction, alveolar wall destruction and oxidant/antioxidant imbalance (3). There is a strong correlation between cigarette smoking and COPD; $\sim 15 \%$ of heavy smokers develop COPD. Compared with non-smoker COPD patients, active smokers exhibit an accelerated decline in lung function and a higher mortality rate (3). Cigarette smoke is a worldwide risk factor in the pathogenesis of COPD, and it is a mixture that contains $>10^{15-17}$ oxidant and free radical molecules and $>5,000$ chemicals per inhalation. These cause oxidative damage and alveolar epithelial cell death, which have been implicated in COPD pathogenesis. Exposure to cigarette smoke-induced oxidative stress becomes a burden to the lungs of smokers (4). Therefore, it is important to investigate potential antioxidant defenses against cigarette smoke-induced cell damage.

Nuclear factor erythroid 2 like 2 (NFE2L2; Nrf2) regulates the antioxidant defense system and, as a central basic leucine zipper transcription factor, modifies oxidative responses and inflammation. Under physiological conditions, Nrf2 is sequestered in the cytoplasm via an interaction with Kelch-like ECH associated protein 1 (Keap1). However, upon exposure to oxidative stimuli, Nrf2 dissociates from Keap1 and translocates into the nucleus, where it dimerizes with Maf proteins and specifically binds to the antioxidant responsive element (ARE) to initiate transcription of target genes. In the absence of oxidative stress, Keap1 suppresses Nrf2 signaling constitutively by preventing Nrf2 translocation to the nucleus (5). Numerous protective antioxidant responses are associated with Nrf2 function. Nrf2 regulates 'direct' and 'indirect' antioxidant enzymes, including superoxide dismutase, $\gamma$-glutamylcysteine synthetase, heme oxygenase-1 and NADPH:quinone oxidoreductase-1, among others. These enzymes exert cytoprotective, antioxidant and anti-inflammatory effects in the respiratory system (6). Upregulation and activation of $\mathrm{Nrf} 2$ enhances expression of antioxidant genes and protects cells from oxidative injury (7). Thus, Nrf2 is an important link between the regulation of antioxidant gene expression and cell survival (8). Deficiency of Nrf2 in a murine model confirmed the direct association between alveolar wall destruction, antioxidant gene regulation and enhanced susceptibility to cigarette smoke-induced emphysema (9). Previous studies have reported that Nrf2 downregulation is linked to increased oxidative stress and pathogenesis in the lungs of patients with COPD $(10,11)$. 
Sulforaphane [1-isothiocyanate-(4R)-(methylsulfinyl) butane; SFN] is a natural isothiocyanate contained in cruciferous vegetables, including broccoli, kale, cole crops and cabbage. Experimental studies have demonstrated that it exhibits cytoprotective effects, particularly against oxidative stress, by inducing the expression of antioxidant enzymes $(12,13)$. SFN induces ARE expression through disruption of the Keap1-Nrf2 complex to release Nrf2, by interacting directly with sulfhydryl residues on Keap1 (14). In addition, SFN activates the MAPK pathway, resulting in phosphorylation of Keap1 and subsequent release of Nrf2 (15). Another study indicated that SFN inhibits Keap1-dependent proteasomal degradation to stabilize the Nrf2 protein (16). Previous studies reported that mice lacking the Nrf2 gene do not develop cancer, if they are treated with broccoli, SFN or other Nrf2-activating drugs $(17,18)$. These reports indicated that the protective effect of broccoli or SFN requires a functional Nrf2 response, and that activation of Nrf2 is involved in protection from free radical-induced diseases, including COPD.

However, the potential protective effect and mechanism of SFN against cigarette smoke extract (CSE)-induced alveolar epithelial cell type II damage has not been fully elucidated to date. The present study aimed to investigate the potential mechanism underlying the protective effects of SFN on RLE-6TN lung epithelial cells. The results demonstrated that SFN attenuated CSE-induced cell injury, and Nrf2 may have an important role in the process.

\section{Materials and methods}

Culture of RLE-6TN cells. The RLE-6TN rat lung epithelial type II cell line was obtained from the Advanced Research Center and Modern Analysis and Testing Center of Central South University (Changsha, China). Cells were grown in Dulbecco's modified Eagle's medium (DMEM; HyClone; GE Healthcare Life Sciences, Logan, UT, USA) supplemented with $10-12 \%$ fetal bovine serum (HyClone; GE Healthcare Life Sciences) and $100 \mathrm{IU} / \mathrm{ml}$ penicillin/streptomycin, in an atmosphere of $5 \% \mathrm{CO}_{2}$ at $37^{\circ} \mathrm{C}$. Cells were subcultured using $0.25 \%$ trypsin and $0.02 \%$ EDTA every 4 to 5 days. Medium was replaced with fresh every 2 days. Cells in the logarithmic phase were used for subsequent experiments.

CSE preparation. CSE was freshly combusted and obtained through an experimental apparatus with an airflow driven continually by vacuum. The smoke from three cigarettes was bubbled into $20 \mathrm{ml}$ DMEM at the rate of one cigarette $/ 2 \mathrm{~min}$. The resulting suspension was regarded as $100 \%$ CSE and diluted to the indicated concentrations with DMEM. The obtained CSE was filtered through a $0.22-\mu \mathrm{m}$ sterile filter prior to addition to cell cultures and was used within $30 \mathrm{~min}$ of preparation. Control group medium was prepared by bubbling air into $20 \mathrm{ml}$ DMEM and filtering.

Cytotoxicity assay. Cell toxicity was determined by an MTT assay. RLE-6TN cells were seeded into 96-well plates at a density of $1 \times 10^{4}$ cells/well. Following cell adherence, complete medium was replaced with serum-free DMEM for $16 \mathrm{~h}$. The cells were subsequently incubated with $1,5,10,15$ or $20 \%$ CSE in serum-free DMEM. After $24 \mathrm{~h}$, MTT reagent $(5 \mathrm{mg} / \mathrm{ml})$ was added into each well and incubated for a further $4 \mathrm{~h}$ at $37^{\circ} \mathrm{C}$, following which crystals were solubilized with $150 \mu \mathrm{l}$ dimethyl sulfoxide (Sigma-Aldrich; Merck KGaA, Darmstadt, Germany). The absorbance was measured at a wavelength of $560 \mathrm{~nm}$ with a BioTek Elx800 plate reader (BioTek Instruments Inc., Winooski, VT, USA).

To observe the effect of SFN (Sigma-Aldrich; Merck $\mathrm{KGaA}$ ) on cell viability, RLE-6TN cells were incubated with $0.5,1,2,4$ or $8 \mu \mathrm{M} \mathrm{SFN}$ in serum-free DMEM. The MTT assay was performed after $24 \mathrm{~h}$ incubation.

Cell cycle analysis. RLE-6TN cells were seeded into 6-well plates at a density of $2 \times 10^{6}$ cells/well. The CSE group was treated with 5\% CSE for $24 \mathrm{~h}$ and the CSE + SFN group was pretreated with $0.5 \mu \mathrm{M} \mathrm{SFN}$ for $12 \mathrm{~h}$ prior to $5 \% \mathrm{CSE}$ treatment for $24 \mathrm{~h}$. The control group was treated with air. Cells were subsequently harvested using $0.25 \%$ trypsin and $0.02 \%$ EDTA, washed three times with PBS by centrifuging at $800 \mathrm{x} \mathrm{g} / \mathrm{min}$ for $5 \mathrm{~min}$ at room temperature and fixed with $70 \%$ pre-chilled ethanol for $12 \mathrm{~h}$ at $4^{\circ} \mathrm{C}$. Cells were washed with PBS again and stained with $50 \mu \mathrm{g} / \mathrm{ml}$ propidium iodide (PI; Sigma-Aldrich; Merck KGaA) for $30 \mathrm{~min}$ in the dark. Finally, cell cycle distribution was detected by flow cytometry and analyzed with Multicycle for Windows (Epics XL; Beckman Coulter, Inc., Brea, CA, USA).

Apoptosis analysis. Apoptosis was determined by a Fluorescein Isothiocyanate (FITC)-conjugated Annexin V/PI Double Staining kit (Sigma-Aldrich; Merck KGaA). RLE-6TN cells were plated, treated and harvested as in the cell cycle analysis section. Cells were subsequently resuspended in $500 \mu \mathrm{l}$ annexin $\mathrm{V}$ binding buffer according to the manufacturer's protocol. Aliquots of the cells were incubated with $5 \mu \mathrm{l}$ annexin V-FITC and $10 \mu \mathrm{l}$ PI at room temperature for $10 \mathrm{~min}$ in the dark. Apoptotic cells were detected by flow cytometry and analyzed with Expo 32 software (Epics XL; Beckman Coulter, Inc.).

Measurement of reactive oxygen species (ROS) levels. RLE-6TN cells were treated with CSE for $24 \mathrm{~h}$ as described above in the cell cycle analysis section, and intracellular ROS levels were detected by staining with 2',7'-dichlorodihydrofluorescein diacetate $\left(\mathrm{H}_{2}\right.$ DCFDA; Sigma-Aldrich; Merck KGaA). $\mathrm{H}_{2}$ DCFDA $(10 \mu \mathrm{M})$ was added to the cell pellet and incubated at $37^{\circ} \mathrm{C}$ for $30 \mathrm{~min}$. Fluorescence was measured by flow cytometry with excitation at a wavelength of $485 \mathrm{~nm}$ and emission at a wavelength of $545 \mathrm{~nm}$, and analyzed with System II software version 3.0 (Epics XL; Beckman Coulter, Inc.).

Morphology. Following CSE treatment, RLE-6TN cell morphological alterations were observed by inverted phase-contrast microscopy and fluorescence microscopy. Cells were washed twice with PBS and stained with $0.5 \mu \mathrm{g} / \mathrm{ml}$ Hoechst 33258 for $10 \mathrm{~min}$ in the dark. Following staining, cells were washed three times with PBS. The nuclear morphology was observed using a Nikon ECLIPSE Ti-U system (Nikon Corporation, Tokyo, Japan). The excitation wavelength was $350 \mathrm{~nm}$. 

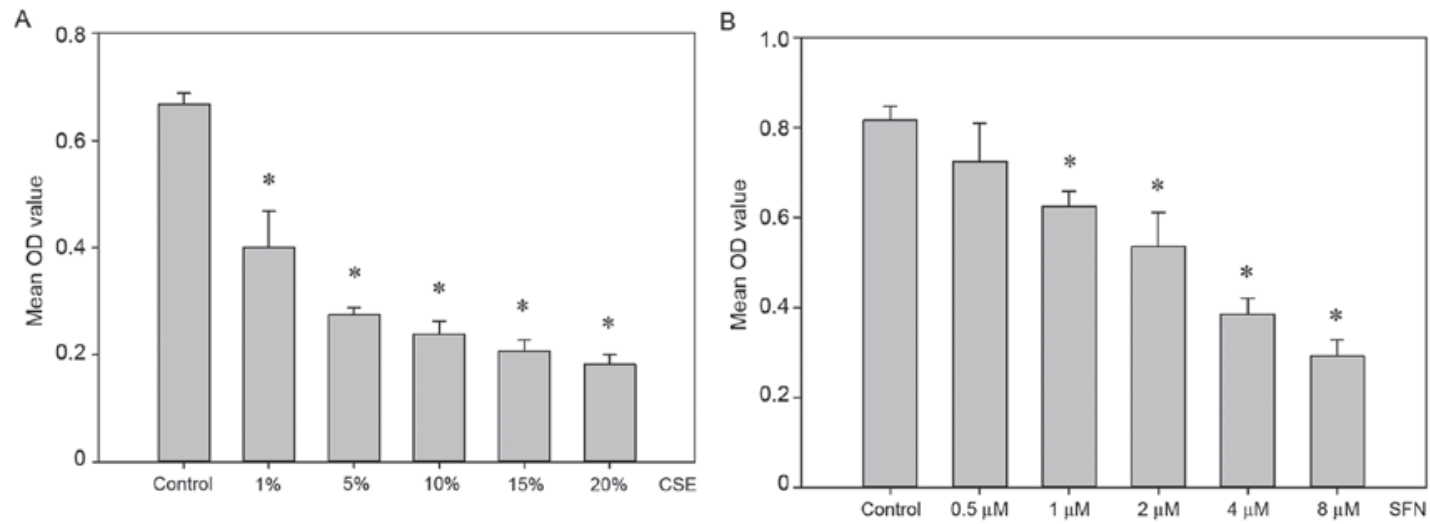

Figure 1. Cell viability was quantified by MTT assay. RLE-6TN cells were treated with various concentrations of (A) CSE and (B) SFN for 24 h. Data are presented as the mean \pm SEM $(n=6) .{ }^{*} \mathrm{P}<0.05$ vs. control. CSE, cigarette smoke extract; SFN, sulforaphane; OD, optical density.

Reverse transcription-quantitative polymerase chain reaction $(R T-q P C R)$. RLE-6TN cells were seeded into 6-well plates at a density of $1 \times 10^{5}$ cells/well. Following serum starvation, SFN pretreatment and CSE treatment as aforementioned, total RNA was isolated using TRIzol ${ }^{\circledR}$ reagent (Takara Biotechnology Co., Ltd., Dalian, China), according to the manufacturer's protocol. RNA samples were reverse-transcribed using the PrimeScript $^{\mathrm{TM}}$ RT Reagent kit (Takara Biotechnology Co., Ltd.), according to the manufacturer's protocol. The cDNA products were used immediately for qPCR, using primers specific for Nrf2 (forward, 5'-CTGCCATTAGTCAGTCGC TCTC-3'; and reverse, 5'-TCGGCTGGGACTTGTGTTC-3') and $\beta$-actin (forward, 5'-GGAGATTACTGCCCTGGC TCCTA-3'; and reverse, 5'-GACTCATCGTACTCCTGC TTGCTG-3'), and the SYBR ${ }^{\circledR}$ Premix Ex Taq TM II kit (Takara Biotechnology Co., Ltd.), according to the manufacturer's protocol. Gene expression was monitored using the Rotor-Gene 3000 system (Qiagen GmbH, Hilden, Germany), following a standardized protocol. In brief, reactions were incubated at $95^{\circ} \mathrm{C}$ for $10 \mathrm{sec}$, and subsequently amplified for 45 cycles at $95^{\circ} \mathrm{C}$ for $5 \mathrm{sec}$ followed by $60^{\circ} \mathrm{C}$ for $20 \mathrm{sec}$ in each cycle. Relative quantification was performed using the following formula: $\Delta \mathrm{C}_{\mathrm{q}}=\mathrm{C}_{\mathrm{q}}$ (target gene) $-\mathrm{C}_{\mathrm{q}}$ ( $\beta$-actin) and fold $=2^{-(\Delta \mathrm{Cq} 2-\Delta \mathrm{Cq} 1)}$, in which $\Delta \mathrm{C}_{\mathrm{q} 1}$ represents the value of control and $\Delta \mathrm{C}_{\mathrm{q} 2}$ represents the value of sample (19). Results were presented as ratios between Nrf2 and the housekeeping reference gene, $\beta$-actin.

Western blot analysis. RLE-6TN cells were plated and treated as in the RT-qPCR section. Total protein was isolated using radioimmunoprecipitation assay lysis buffer (Applygen Technologies, Inc., Beijing, China), according to the manufacturer's protocol. After centrifugation at with $10,000 \mathrm{x} \mathrm{g} / \mathrm{min}$ for $20 \mathrm{~min}$ at $4^{\circ} \mathrm{C}$, the protein concentration of the supernatant was determined using a Bicinchoninic Acid Protein assay kit (Applygen Technologies, Inc.). Protein samples (40 $\mu \mathrm{g})$ were separated on $12 \%$ polyacylamide gels at $120 \mathrm{~V}$ for $2.5 \mathrm{~h}$ and transferred onto polyvinylidene difluoride membranes at $250 \mathrm{~mA}$ for $1.5 \mathrm{~h}$. Membranes were blocked with $5 \%$ non-fat milk powder in TBS containing $0.1 \%$ Tween-20 (TBST) for $1 \mathrm{~h}$ at room temperature and subsequently probed with a polyclonal rabbit anti-Nrf2 antibody (cat. no. ab31163; 1:1,000;
Abcam, Cambridge, UK) or a mouse anti- $\beta$-actin antibody (cat. no. ab8226; 1:1,000; Abcam) overnight at $4^{\circ} \mathrm{C}$. Following three washes with TBST, DyLight 800-labeled goat anti-rabbit/mouse secondary antibodies (cat. nos.042-07-15-06 and 042-07-18-06, respectively; 1:10,000; SeraCare Life Sciences, Inc., Milford, MA, USA) were incubated with membranes for $1 \mathrm{~h}$ at room temperature. The bands were detected using an Odyssey Infrared Imaging System (LI-COR Biosciences, Lincoln, NE, USA) and analyzed with ImageJ software version $1.50 \mathrm{i}$ (National Institutes of Health, Bethesda, Maryland, USA).

Statistical analysis. Experimental data are presented as the mean \pm standard error. SPSS software version 21.0 (IBM SPSS, Armonk, NY, USA) was used to analyze statistical significance between groups by paired Student's t-test or one-way analysis of variance followed by Fisher's least significant difference post hoc test. $\mathrm{P}<0.05$ was considered to indicate a statistically significant difference.

\section{Results}

SFN treatment protects against CSE-induced cell injury. Following adherence, RLE-6TN lung epithelial cells were exposed to different concentrations of CSE $(1,5,10,15$ or 20\%) for $24 \mathrm{~h}$. Cell viability was subsequently measured by MTT assay. As demonstrated in Fig. 1A, CSE treatment resulted in a significant decrease in cell viability compared with control cells, in a dose-dependent manner $(\mathrm{P}<0.05)$. A concentration of 5\% CSE was selected for further experiments as it reduced cell viability by $\sim 50 \%$ and cells also remained attached to the bottom of the flask.

To examine the cytotoxic effect of SFN on RLE-6TN cells and to select the appropriate concentration to pretreat cells for further experiments, another MTT assay was performed. Cells were exposed to different concentrations of SFN $(0.5,1,2,4$ or $8 \mu \mathrm{M}$ ) for $24 \mathrm{~h}$. As demonstrated in Fig. 1B, no significant difference was observed in the $0.5 \mu \mathrm{M}$ SFN treatment group compared with the control untreated group $(\mathrm{P}>0.05)$. Therefore, this concentration was selected for the pretreatment of cells in subsequent experiments.

By Hoechst 33258 staining, cells treated with CSE exhibited a shrunken morphology and nuclei fragmentation 
Table I. Cell cycle progression, apoptosis and ROS levels were assessed by flow cytometry.

\begin{tabular}{lccr}
\hline & & \multicolumn{2}{c}{ Group } \\
\cline { 2 - 4 } Parameter & Control & CSE & SFN + CSE \\
\hline Proportion in G1 phase (\%) & $60.56 \pm 3.68$ & $65.88 \pm 2.78$ & $58.69 \pm 3.94$ \\
Proportion in S phase (\%) & $22.26 \pm 0.24$ & $12.84 \pm 0.52^{\mathrm{a}}$ & $19.98 \pm 0.52^{\mathrm{b}}$ \\
Apoptotic proportion (\%) & $0.16 \pm 0.21$ & $78.08 \pm 0.97^{\mathrm{a}}$ & $6.12 \pm 0.33^{\mathrm{a}, \mathrm{b}}$ \\
ROS levels (\%) & $20.87 \pm 0.94$ & $86.63 \pm 1.21^{\mathrm{a}}$ & $28.03 \pm 0.26^{\mathrm{a}, \mathrm{b}}$ \\
\hline
\end{tabular}

Data are presented as the mean \pm standard error $(n=3) .{ }^{a} \mathrm{P}<0.05$ vs. control; ${ }^{\mathrm{b}} \mathrm{P}<0.05$ vs. CSE. Control, untreated; CSE, treated with $5 \% \mathrm{CSE}$ for $24 \mathrm{~h}$; SFN + CSE, pretreated with $0.5 \mu \mathrm{M} \mathrm{SFN}$ and treated with $5 \%$ CSE for $24 \mathrm{~h}$. CSE, cigarette smoking extract; SFN, sulforaphane; ROS, reactive oxygen species.
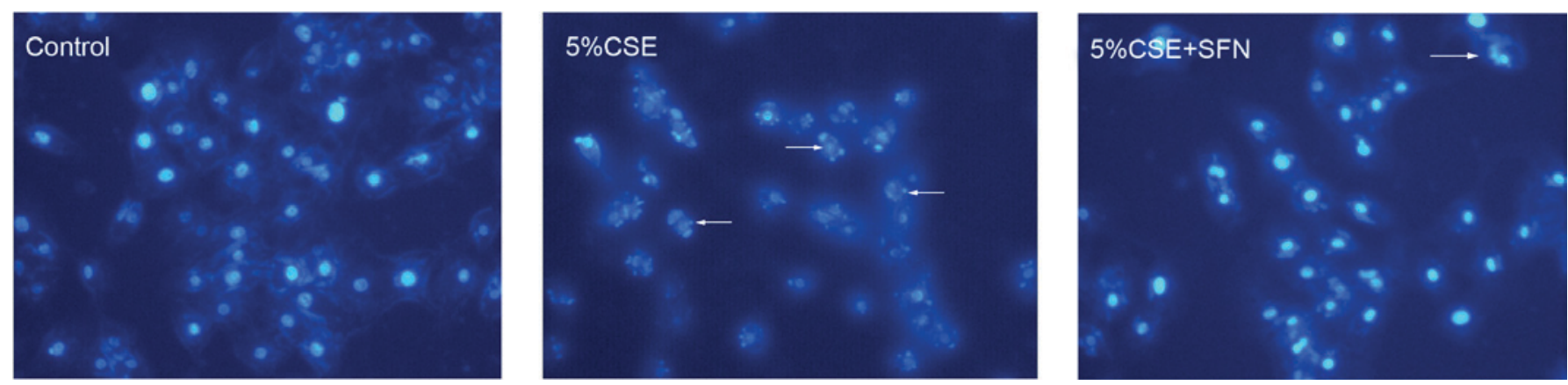

Figure 2. Hoechst 33258 staining revealed the morphological characteristics of cells. Control, untreated; 5\% CSE, treated with 5\% CSE for 24 h; $5 \%$ CSE + SFN, pretreated with $0.5 \mu \mathrm{M} \mathrm{SFN}$ and treated with 5\% CSE for $24 \mathrm{~h}$. Following treatment, cells were stained with Hoechst 33258. Cells were observed under an inverted fluorescence microscope. Original magnification, x200. Arrows indicate nuclei fragmentation. CSE, cigarette smoke extract; SFN, sulforaphane.

A

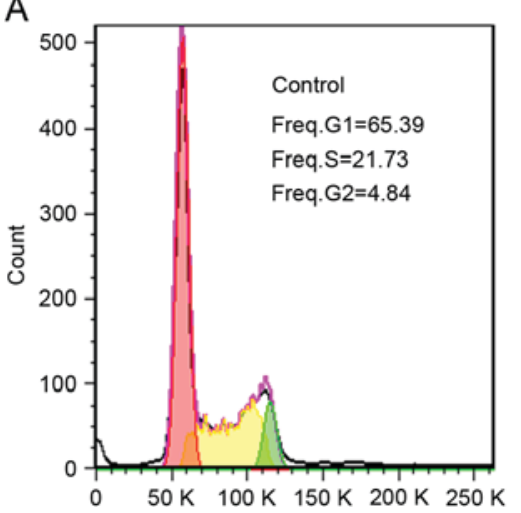

B

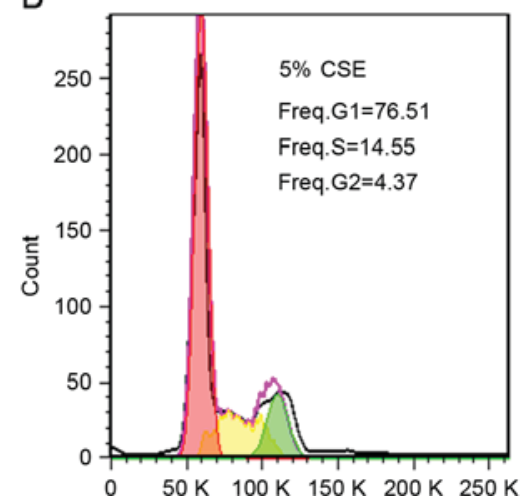

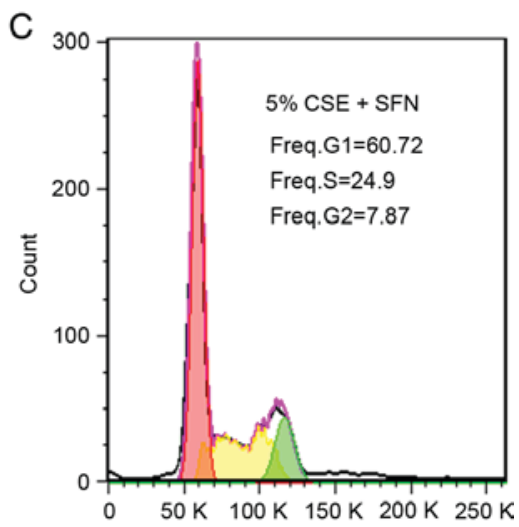

Figure 3. Effects of CSE and SFN on cell cycle progression. (A) Control untreated cells, (B) cells treated with 5\% CSE for $24 \mathrm{~h}$ and (C) cells pretreated with $0.5 \mu \mathrm{M}$ SFN and treated with 5\% CSE for $24 \mathrm{~h}$. Cell cycle analysis was measured using propidium iodide staining. Red, G1 phase; Yellow, S phase; and Green, G2/M phase. CSE, cigarette smoke extract; SFN, sulforaphane.

compared with control air-treated cells (Fig. 2). These morphological characteristics are features of apoptotic cells. Following pretreatment with SFN for $12 \mathrm{~h}$, the cells exposed to CSE exhibited no clear alterations in morphology compared with control cells (Fig. 2), suggesting that SFN had a protective effect against CSE.

To further confirm the protective effect of SFN against CSE on lung epithelial cells, cell cycle analysis was performed. The results demonstrated that, in the control group, the percentage of cells in the G1 phase was $60.56 \pm 3.68 \%$ and in the $\mathrm{S}$ phase was $22.26 \pm 0.24 \%$ (Fig. 3A; Table I). Following treatment with 5\% CSE, the proportion of cells in the G1 phase increased to $65.88 \pm 2.78 \%$, whereas the proportion in the $\mathrm{S}$ phase decreased to $12.84 \pm 0.52 \%$ (Fig. 3B; Table I). However, pretreatment with SFN reversed this effect, with the percentage of cells in the $\mathrm{G} 1$ and $\mathrm{S}$ phases recovering to $58.69 \pm 3.94$ and $19.98 \pm 0.52 \%$, respectively (Fig. 3C; Table I). Although the difference in G1 phase values between the groups was not statistically significant, similar changes in the mean values between control, CSE and CSE + SFN groups were observed in several independent experiments, these results indicate that CSE may inhibit cell growth by inducing 


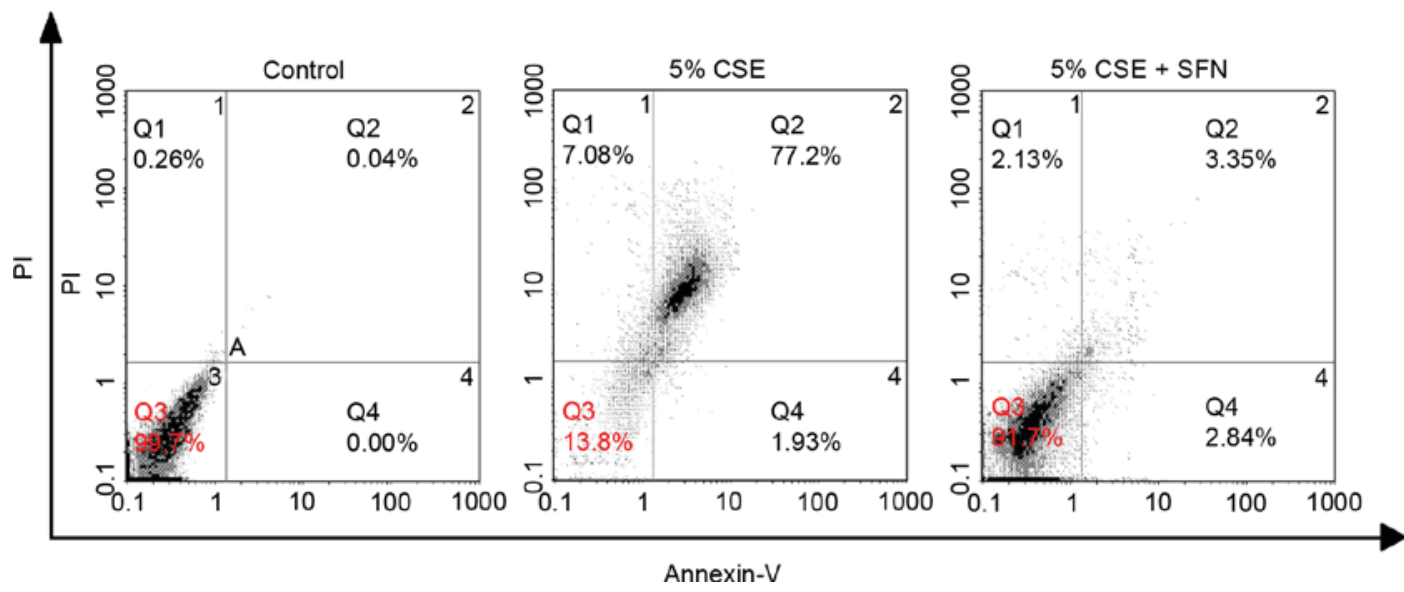

Figure 4. Effects of CSE and SFN on apoptosis. Control, untreated; $5 \%$ CSE, treated with $5 \%$ CSE for $24 \mathrm{~h} ; 5 \%$ CSE + SFN, pretreated with $0.5 \mu \mathrm{M}$ SFN and treated with 5\% CSE for $24 \mathrm{~h}$. Apoptosis was detected using annexin V-fluorescein isothiocyanate/PI double staining. Cells in the Q2 and Q4 quadrants (annexin $\mathrm{V}^{+} / \mathrm{PI}^{+}$and annexin $\mathrm{V}^{+} / \mathrm{PI}^{-}$, respectively) were considered to be apoptotic. CSE, cigarette smoke extract; SFN, sulforaphane; PI, propidium iodide.
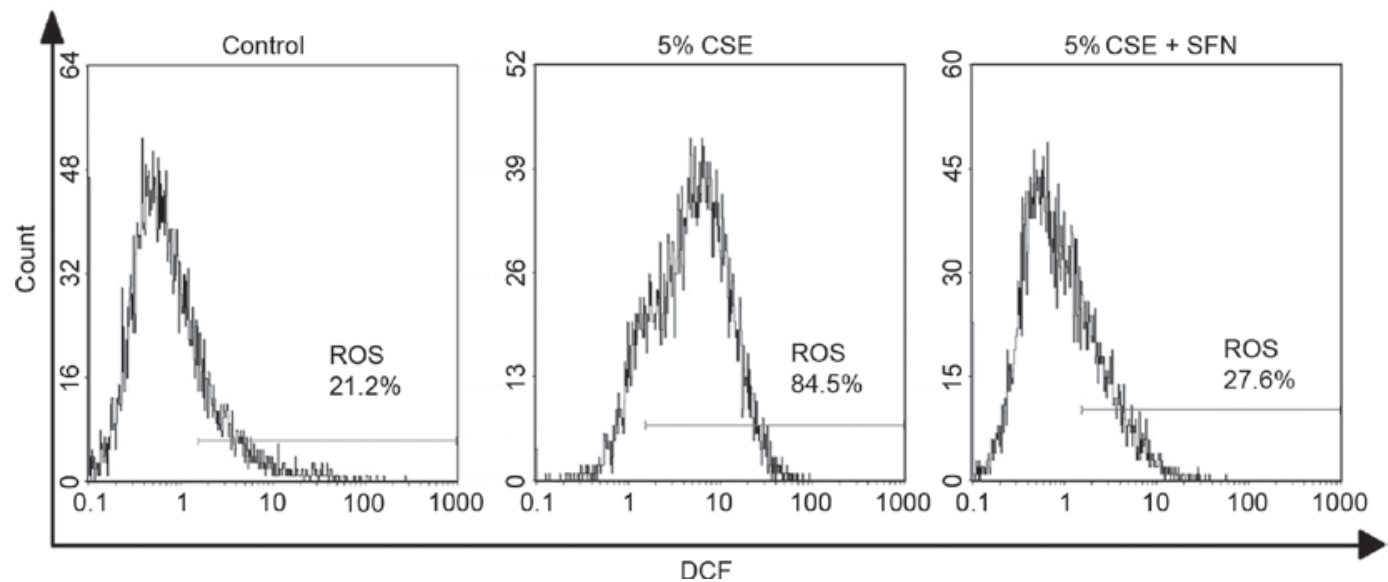

Figure 5. Effects of CSE and SFN on ROS levels. Control, untreated; 5\% CSE, treated with 5\% CSE for $24 \mathrm{~h} ; 5 \% \mathrm{CSE}+\mathrm{SFN}$, pretreated with $0.5 \mu \mathrm{M}$ SFN and treated with 5\% CSE for $24 \mathrm{~h}$. ROS were detected using 2',7'-dichlorodihydrofluorescein diacetate, and the percentage of ROS-positive cells was determined. CSE, cigarette smoke extract; SFN, sulforaphane; ROS, reactive oxygen species.

cell cycle arrest in the G1 phase, and that SFN may protect cells against CSE.

Apoptotic cell death induced by CSE in the presence or absence of SFN pretreatment was additionally quantified using annexin V-FITC/PI double staining. As demonstrated in Table I and Fig. 4, the percentage of apoptotic cells (Q2+Q4 quadrants) in the control group was $0.16 \pm 0.21 \%$, whereas this was increased to $78.08 \pm 0.97 \%$ in the CSE treatment group. SFN pretreatment again exhibited a protective effect against CSE-induced apoptosis, with the percentage of apoptotic cells decreasing to $6.12 \pm 0.33 \%$ in the SFN group.

Finally, the $\mathrm{H}_{2}$ DCFDA probe was used to examine intracellular ROS levels. The results demonstrated that CSE increased intracellular ROS levels, with $86.63 \pm 1.21 \%$ positive cells, compared with $20.87 \pm 0.94 \%$ in the control cells; this percentage was decreased to $28.03 \pm 0.26 \%$ by pretreatment with SFN (Fig. 5; Table I).

SFN increases Nrf2 expression levels following CSE exposure. The mRNA expression levels of Nrf2 were quantified by RT-qPCR. Following pretreatment with SFN for $12 \mathrm{~h}$ and exposure to CSE for $24 \mathrm{~h}$, Nrf2 mRNA expression levels were significantly elevated ( $>8$-fold or $>2$-fold) compared with the control group or CSE-only group $(\mathrm{P}<0.05 ; \mathrm{n}=3$; Fig. 6$)$.

The protein levels of Nrf2 were detected by western blotting, and were consistent with the RT-qPCR data. The SFN group had significantly increased protein levels of Nrf2 compared with control and CSE groups (Fig. 7).

\section{Discussion}

Alveolar epithelial cells are comprised of two primary types, I and II. Although the surface area occupied by type II cells is small, it may serve an important role in lung function. A primary culture, despite representing the best experimental system, is not suitable for long-term experiments as type II cells will transdifferentiate into type I-like cells. Thus, the RLE-6TN cell line is a useful and appropriate immortalized cell line for the study of alveolar cell function due to its similarity to alveolar type II epithelial cells (20).

Cigarette smoke is well known to induce oxidative stress and serve a pathological role in CSE-induced lung diseases including COPD. Alveolar epithelial cells represent the initial target of CSE. It is therefore essential to protect 


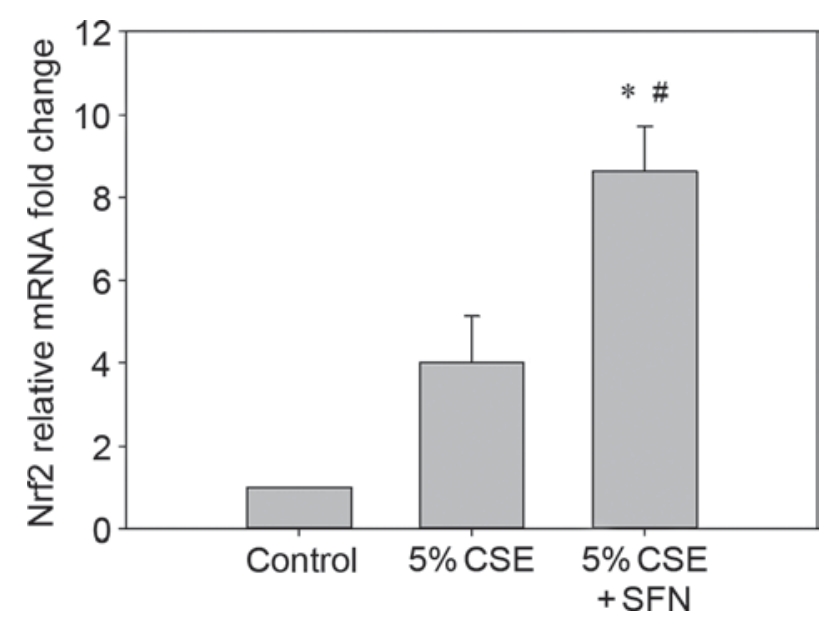

Figure 6. Nrf2 mRNA expression levels were measured using reverse transcription-quantitative polymerase chain reaction. Control, untreated; 5\% CSE, treated with 5\% CSE for $24 \mathrm{~h} ; 5 \% \mathrm{CSE}+\mathrm{SFN}$, pretreated with $0.5 \mu \mathrm{M}$ SFN and treated with 5\% CSE for $24 \mathrm{~h}$. Data are presented as the mean \pm standard error $(n=3) .{ }^{*} \mathrm{P}<0.05$ vs. control; ${ }^{*} \mathrm{P}<0.05$ vs. $5 \%$ CSE. CSE, cigarette smoke extract; SFN, sulforaphane; Nrf2, Nrf2, nuclear factor erythroid 2 like 2.

alveolar epithelial cells from oxidative stress injury induced by CSE $(21,22)$.

SFN is chemically defined as an isothiocyanate, and is abundant in cruciferous vegetables including broccoli and Brussels sprouts. For a long time, SFN has been considered a cytoprotective agent based on its ability to induce and activate antioxidant enzymes. A concentration of $0.5 \mu \mathrm{M}$ SFN did not significantly reduce cell viability in the present study, however, SFN may be toxic at higher concentrations as observed in the in vitro MTT assay of the present study, which may limit the use of high doses of SFN. The Nrf2-ARE pathway has been investigated as a potential underlying mechanism. Nrf2 is known to be activated by phosphorylation. Various protein kinase pathways lead to Keap1-Nrf2 dissociation, and Nrf2 translocation from the cytoplasm to the nucleus to bind to the ARE. Nrf2 is largely responsible for the basal and inducible expression of proteins involved in drug metabolism, the oxidative stress response and cytoprotection (23).

The present study investigated the effects of SFN on CSE-induced toxicity in RLE-6TN cells.

Using 5\% CSE to stimulate RLE-6TN cells following pretreatment with $0.5 \mu \mathrm{M} \mathrm{SFN}$ for $12 \mathrm{~h}$, the results of the present study suggested that SFN-induced Nrf2 may serve an important role in protecting RLE-6TN cells from oxidative injury caused by CSE. Compared with the CSE and control groups, the SFN group exhibited significantly increased levels of Nrf 2 and attenuated CSE-induced cell injury. The possible mechanism underlying Nrf2 protection is that the activation of Nrf2 may promote the synthesis and release of antioxidant enzymes through the Nrf2-ARE pathway. In addition, the results of the present study demonstrated a reduction in the percentage of cells in the S phase following CSE treatment; and SFN pretreatment alleviated this reduction, which indicated that SFN may have its protective role by modulating the cell cycle; however, the underlying mechanisms remain unclear. Apoptosis was induced by CSE and the effects of
A

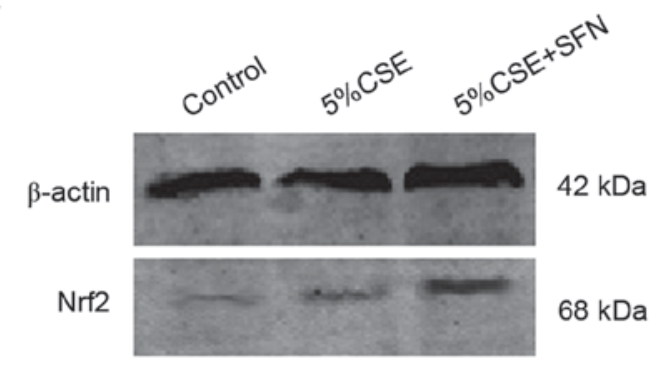

B

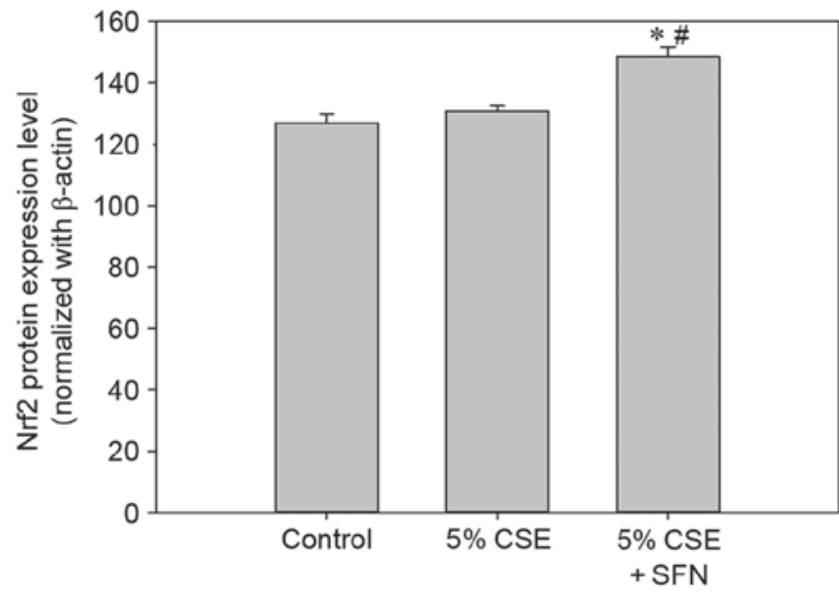

Figure 7. Nrf2 protein expression levels were assessed by western blot analysis. (A) Images and (B) densitometry of western blots. Control, untreated; $5 \%$ CSE, treated with 5\% CSE for $24 \mathrm{~h} ; 5 \% \mathrm{CSE}+\mathrm{SFN}$, pretreated with $0.5 \mu \mathrm{M}$ SFN and treated with $5 \% \mathrm{CSE}$ for $24 \mathrm{~h}$. Data are presented as the mean \pm standard error $(n=3)$. ${ }^{*} \mathrm{P}<0.05$ vs. control; ${ }^{\#} \mathrm{P}<0.05$ vs. $5 \%$ CSE. CSE, cigarette smoke extract; SFN, sulforaphane; Nrf2, Nrf2, nuclear factor erythroid 2 like 2 .

SFN pretreatment were in accordance with the morphological observations reported by Kosmider et al (24). Furthermore, ROS serves a critical role in lung epithelial cell damage, particularly in CSE-induced injury. The results of the present study suggested that the Nrf2-ARE pathway may promote antioxidant enzymes and reduce ROS levels in the cell. These findings support the hypothesis that SFN may protect alveolar epithelial cells from CSE injury by activating the Nrf2-ARE pathway.

In conclusion, the results of the present study indicate that CSE inhibits RLE-6TN cell proliferation and induces apoptosis. Pretreatment with SFN may alleviate cell injury and reduce ROS damage, potentially via increased Nrf2 expression. These results suggest that Nrf2 may be a potential therapeutic target for the treatment of COPD.

\section{Acknowledgements}

Zongxian Jiao was supported by the Fundamental Research Funds for the Central Universities (grant no. lzujbky-2013-223) and the Project sponsored by The Scientific Research Foundation for Returned Overseas Chinese Scholars (State Education Ministry, Beijing, China). 


\section{References}

1. Jansson SA, Backman H, Stenling A, Lindberg A, Rönmark E and Lundbäck B: Health economic costs of COPD in Sweden by disease severity-has it changed during a ten years period? Respir Med 107: 1931-1938, 2013.

2. Decramer M, Janssens W and Miravitlles M: Chronic obstructive pulmonary disease. Lancet 379: 1341-1351, 2012.

3. Tamimi A, Serdarevic D and Hanania NA: The effects of cigarette smoke on airway inflammation in asthma and COPD: Therapeutic implications. Respir Med 106: 319-328, 2012.

4. Zhang H, Shih A, Rinna A and Forman HJ: Exacerbation of tobacco smoke mediated apoptosis by resveratrol: An unexpected consequence of its antioxidant action. Int J Biochem Cell Biol 43: 1059-1064, 2011.

5. Goven D, Boutten A, Leçon-Malas V, Boczkowski J and Bonay M: Prolonged cigarette smoke exposure decreases heme oxygenase- 1 and alters Nrf2 and Bach1 expression in human macrophages: Roles of the MAP kinases ERK $(1 / 2)$ and JNK. FEBS Lett 583: 3508-3518, 2009.

6. Regoli $\mathrm{F}$ and Giuliani ME: Oxidative pathways of chemical toxicity and oxidative stress biomarkers in marine organisms. Mar Environ Res 93: 106-117, 2014

7. Tasaki M, Kuroiwa Y, Inoue T, Hibi D, Matsushita K, Kijima A, Maruyama S, Nishikawa A and Umemura T: Lack of nrf 2 results in progression of proliferative lesions to neoplasms induced by long-term exposure to non-genotoxic hepatocarcinogens involving oxidative stress. Exp Toxicol Pathol 66: 19-26, 2014.

8. Cano M, Thimmalappula R, Fujihara M, Nagai N, Sporn M, Wang AL, Neufeld AH, Biswal S and Handa JT: Cigarette smoking, oxidative stress, the anti-oxidant response through Nrf2 signaling and Age-related macular degeneration. Vision Res 50: 652-664, 2010.

9. Rangasamy T, Cho CY, Thimmulappa RK, Zhen L, Srisuma SS, Kensler TW, Yamamoto M, Petrache I, Tuder RM and Biswal S: Genetic ablation of Nrf2 enhances susceptibility to cigarette smoke-induced emphysema in mice. J Clin Invest 114: 1248-1259, 2004.

10. Suzuki M, Betsuyaku T, Ito Y, Nagai K, Nasuhara Y, Kaga K, Kondo S and Nishimura M: Down-regulated NF-E2-related factor 2 in pulmonary macrophages of aged smokers and patients with chronic obstructive pulmonary disease. Am J Respir Cell Mol Biol 39: 673-682, 2008.

11. Malhotra D, Thimmulappa R, Navas-Acien A, Sandford A, Elliott M, Singh A, Chen L, Zhuang X, Hogg J, Pare P, et al: Expression of concern: Decline in NRF2-regulated antioxidants in chronic obstructive pulmonary disease lungs due to loss of its positive regulator, DJ-1. Am J Respir Crit Care Med 178 592-604, 2008
12. Ping Z, Liu W, Kang Z, Cai J, Wang Q, Cheng N, Wang S, Wang S, Zhang JH and Sun X: Sulforaphane protects brains against hypoxic-ischemic injury through induction of Nrf2-dependent phase 2 enzyme. Brain Res 1343: 178-185, 2010.

13. Guerrero-Beltrán CE, Calderón-Oliver M, Pedraza-Chaverri J and Chirino YI: Protective effect of sulforaphane against oxidative stress: Recent advances. Exp Toxicol Pathol 64: 503-508, 2012.

14. Bergström P, Andersson HC, Gao Y, Karlsson JO, Nodin C, Anderson MF, Nilsson M and Hammarsten O: Repeated transient sulforaphane stimulation in astrocytes leads to prolonged Nrf2-mediated gene expression and protection from superoxide-induced damage. Neuropharmacology 60: 343-353, 2011.

15. Hu R, Hebbar V, Kim BR, Chen C, Winnik B, Buckley B, Soteropoulos P, Tolias P, Hart RP and Kong AN: In vivo pharmacokinetics and regulation of gene expression profiles by isothiocyanate sulforaphane in the rat. J Pharmacol Exp Ther 310: 263-271, 2004.

16. Kobayashi A, Kang MI, Okawa H, Ohtsuji M,Zenke Y, Chiba T, Igarashi $\mathrm{K}$ and Yamamoto M: Oxidative stress sensor Keap1 functions as an adaptor for Cul3-based E3 ligase to regulate proteasomal degradation of Nrf2. Mol Cell Biol 24: 7130-7139, 2004.

17. Iida K, Itoh K, Kumagai Y, Oyasu R, Hattori K, Kawai K, Shimazui T, Akaza H and Yamamoto M: Nrf2 is essential for the chemopreventive efficacy of oltipraz against urinary bladder carcinogenesis. Cancer Res 64: 6424-6431, 2004.

18. Xu C, Huang MT, Shen G, Yuan X, Lin W, Khor TO, Conney AH and Kong AN: Inhibition of 7,12-dimethylbenz(a) anthracene-induced skin tumorigenesis in C57BL/6 mice by sulforaphane is mediated by nuclear factor E2-related factor 2 . Cancer Res 66: 8293-8296, 2006.

19. Burkhardt BR, Lyle R, Qian K, Arnold AS, Cheng H, Atkinson MA and Zhang YC: Efficient delivery of siRNA into cytokine-stimulated insulinoma cells silences Fas expression and inhibits Fas-mediated apoptosis. FEBS Lett 580: 553-560, 2006.

20. Oda K, Yumoto R, Nagai J, Katayama H and Takano M: Mechanism underlying insulin uptake in alveolar epithelial cell line RLE-6TN. Eur J Pharmacol 672: 62-69, 2011.

21. Nadigel J, Audusseau S, Baglole CJ, Eidelman DH and Hamid Q: IL-8 production in response to cigarette smoke is decreased in epithelial cells from COPD patients. Pulm Pharmacol Ther 26: 596-602, 2013

22. Thorne D and Adamson J: A review of in vitro cigarette smoke exposure systems. Exp Toxicol Pathol 65: 1183-1193, 2013.

23. Bryan HK, Olayanju A, Goldring CE and Park BK: The Nrf 2 cell defence pathway: Keap1-dependent and -independent mechanisms of regulation. Biochem Pharmacol 85: 705-717, 2013.

24. Kosmider B, Messier EM, Chu HW and Mason RJ: Human alveolar epithelial cell injury induced by cigarette smoke. PLoS One 6: e26059, 2011. 